\title{
Exposure of the French population to ionizing radiations from medical diagnostic procedures in 2012
}

\author{
S. Dreuil ${ }^{*}$ and C. Etard \\ IRSN, Medical Radiation Protection Unit, BP 17, 92262 Fontenay-aux-Roses Cedex, France.
}

Received: 12 October 2016 / Accepted: 22 January 2017

\begin{abstract}
Monitoring the exposure of the population to ionizing radiation is a European Union requirement. This article presents the exposure of the French population originating from medical diagnostic procedures performed in 2012. The number of procedures was established from a joint health insurances database. The effective dose associated with each procedure was estimated from various sources (national DRL, recent surveys, guides of procedures). The number of procedures was approximately 81.8 million, representing an average of 1247 examinations per 1000 inhabitants. The mean effective dose per inhabitant originating from medical diagnosis exposure was $1.6 \mathrm{mSv}$. When restricted to the population actually exposed, the average number of examinations was 2760 per 1000 individuals and the mean effective dose per exposed individual was $3.4 \mathrm{mSv}$. 70\% of exposed individuals received less than $1 \mathrm{mSv}$. Mean individual exposure strongly increased with age: below $1 \mathrm{mSv}$ before the age of 20, around $7 \mathrm{mSv}$ at 75 years. $44 \%$ of the French population (49\% of the women, 39\% of the men) has benefited from at least one diagnosis procedure. Conventional radiology, dental radiology and computed tomography represented respectively $54 \%, 34 \%$ and $10.5 \%$ of the number of procedures and contributed to $18 \%, 0.2 \%$ and $71 \%$ of the collective effective dose, respectively. A $20 \%$ increase of the average effective dose per inhabitant was observed, when compared to the year 2007. While efforts are still needed in the optimization of delivered dose and in the harmonization of practices, whatever the imaging field, specific interest should be paid to the justification of certain examinations which have particularly increased in numbers.
\end{abstract}

Keywords: radiation exposure / diagnostic imaging / population exposure

\section{Introduction}

In accordance with the requirements of the European Union Council directives 97/43/EURATOM and 2013/59/ EURATOM (EU Council, 1997, 2013), the Institute for Radiological Protection and Nuclear Safety (IRSN) is periodically monitoring the exposure of the French population to ionizing radiation. The exposure related to medical diagnosis examinations performed during the year 2012 has been assessed in a study published in 2014 (IRSN, 2014a). Two previous studies had focused on the years 2002 and 2007 (IRSN, 2006, 2010). In particular, the characteristics of the medical exposure by imaging modality (conventional radiology, computed tomography, diagnostic interventional radiology and diagnostic nuclear medicine), by explored anatomic region, by patients' age and sex was investigated, as well as the part of the French population (numbers, age and sex) who actually undergone medical diagnostic examination in 2012.

\footnotetext{
* Corresponding author: serge.dreuil@irsn.fr
}

The complete analysis of the study is available online ${ }^{1}$, in French only. The purpose of this article is to present the main results of the study to non-francophone readers.

\section{Material and methods}

The examination frequency was estimated from the Échantillon Généraliste de Bénéficiaires (EGB). The EGB is a permanent representative sample of the population protected by French health insurance (De Roquefeuil et al., 2009). EGB is based on a survey on about $1 \%$ of the beneficiaries from the three main French health insurance schemes (Régime général, RSA and RSI), whether these beneficiaries have received healthcare reimbursements or not. The three health insurance schemes cited above currently cover around $85 \%$ of beneficiaries of all French social security schemes. Characterization of the population actually exposed in 2012, in numbers, sex and age, was also established from the EGB database.

\footnotetext{
${ }^{1}$ http://www.irsn.fr/FR/expertise/rapports_expertise/radioprotectionhomme/Pages/Rapport-IRSN-HOM-2014-006_Exposition-rayonne ments-ionisants-diagnostic-medical.aspx.
} 

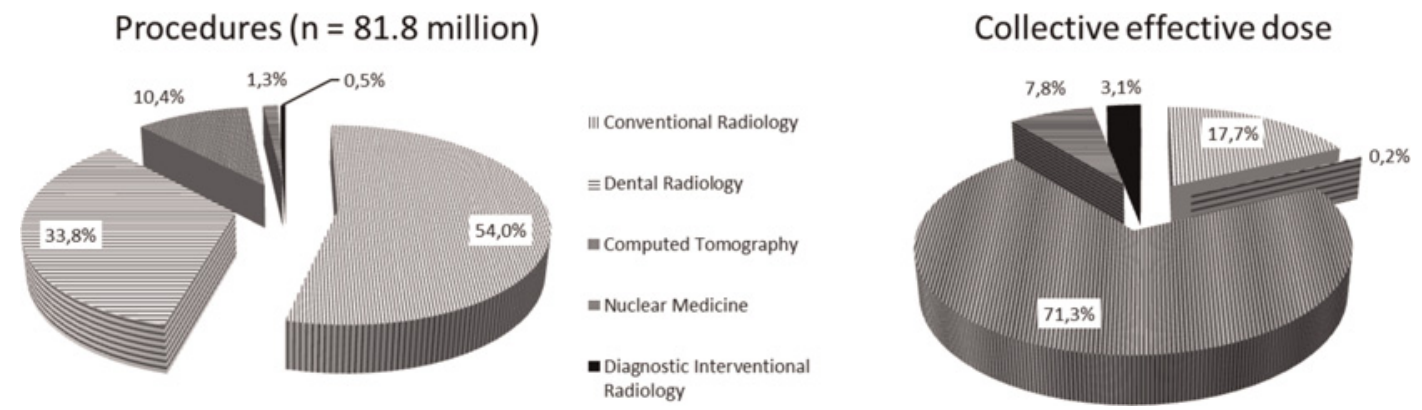

Fig. 1. Proportion of the number of radiodiagnosis procedures and of the associated collective effective dose in 2012 , according to the imaging modality.

The average effective dose was calculated for each type of medical diagnosis procedure, using mainly the data transmitted to the IRSN as part of the update of national diagnostic reference levels (IRSN, 2013), the results of recent national surveys (IRSN, 2011, 2014b; Etard and Aubert, 2012; Etard et al., 2012a) and the guides of procedures established by professionals (SFR, 2004, 2013; HAS, 2006; SFMN, 2012; Georges et al., 2014). Uncertainty on the procedures' average effective dose was estimated to more than $50 \%$, on a general basis and following recommended methods (European Commission, 2008; Etard et al., 2012b). Sources of uncertainties were essentially: (a) dispersion of the delivered effective doses for a given type of procedure at a national level, due to variations in protocols or equipment; (b) inconsistencies between the national codification and the actual clinical practices; and (c) rarity of certain types of procedures.

\section{Results}

The number of medical diagnosis procedures using ionizing radiation is estimated at approximately 81.8 million in 2012. It represents an average of 1247 examinations for 1000 inhabitants. The mean effective dose per inhabitant originating from medical exposure is estimated to $1.6 \mathrm{mSv}$ for the year 2012 .

Conventional radiology, dental radiology and computed tomography represent respectively $54 \%, 34 \%$ and $10.5 \%$ of the number of procedures. These three imaging modalities contribute respectively for $18 \%, 0.2 \%$ and $71 \%$ of the collective effective dose (Fig. 1).

In 2012, about $44 \%$ of the French population has benefited from at least one diagnosis procedure. This percentage rises from $18 \%$ among children aged less than 5 years to approximately $60 \%$ among adults aged around 70 years (Fig. 2). Women are more likely to receive a radiodiagnosis: $49 \%$ of the female population underwent at least one diagnosis procedure, whereas this figure is $39 \%$ only for the male population. The differences between the two genders are particularly obvious for the adults aged $30-80$ years, as it is depicted in Figure 2. A significant peak can also be observed for children and adolescents aged 10-19 years, who are roughly $10 \%$ more likely to undergo a radiodiagnosis than the young adults aged 20-29 years.

When restricted to the population actually exposed, the mean number of examinations is 2760 for 1000 individuals in 2012. Figure 3 illustrates the distribution of the mean number

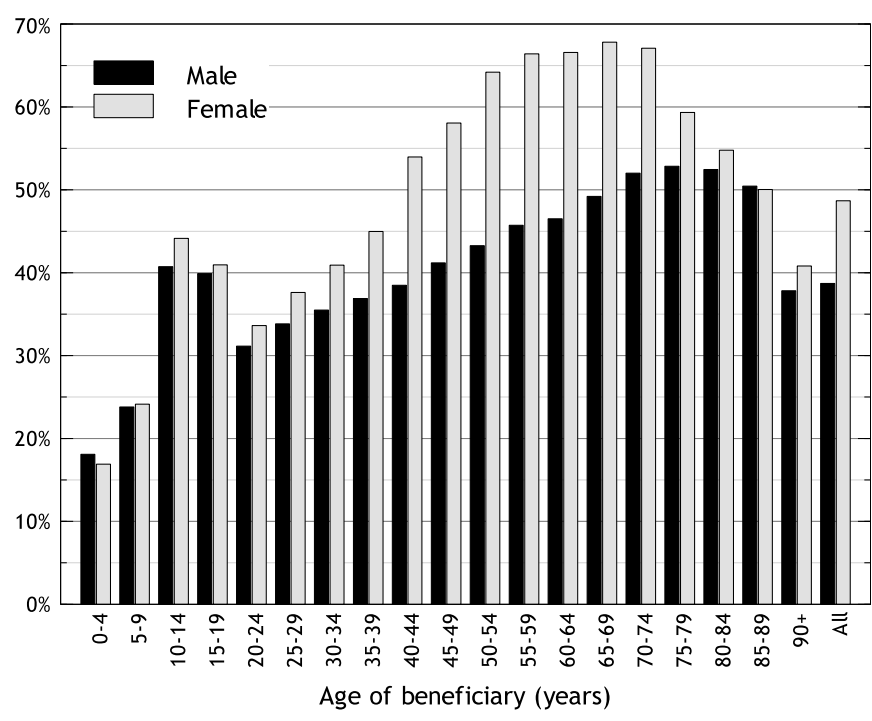

Fig. 2. Proportion of beneficiaries from the three major French health insurance schemes who received at least one radiodiagnostic procedure in 2012, by sex and age category.

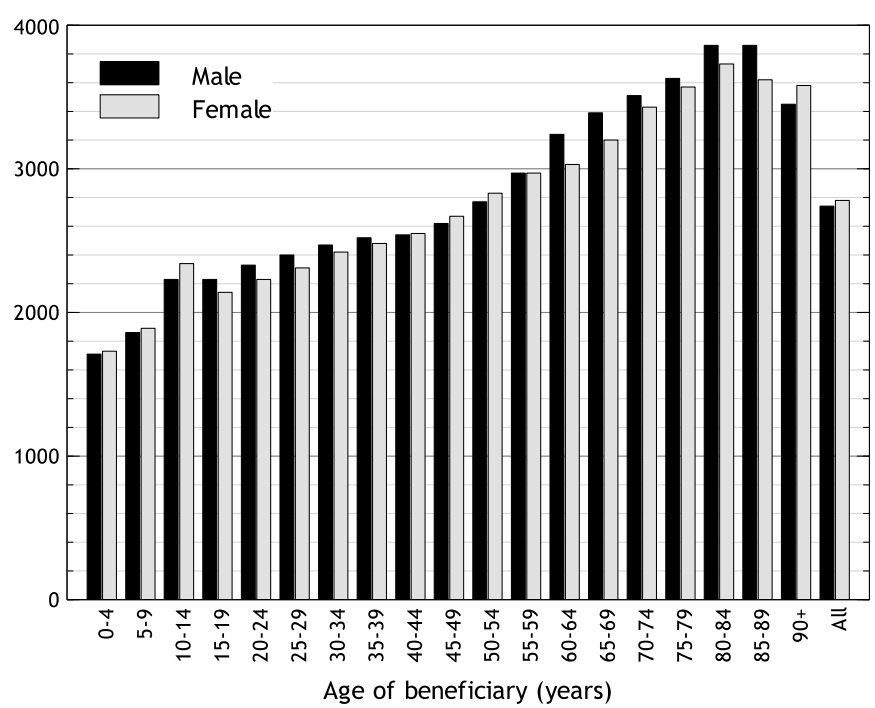

Fig. 3. Age and sex distribution of the mean number of radiodiagnosis examinations per 1000 exposed individuals. 

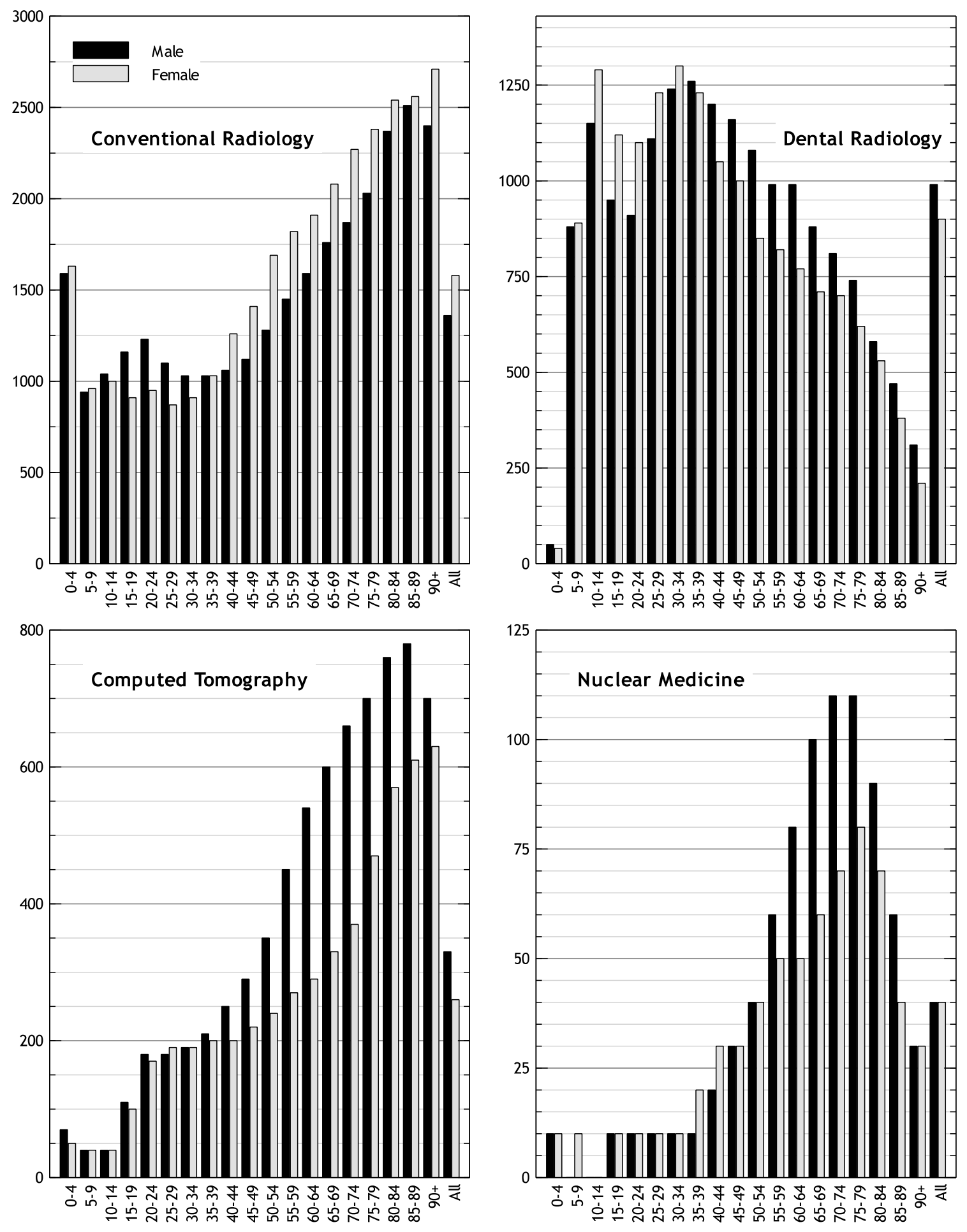

Age (years)

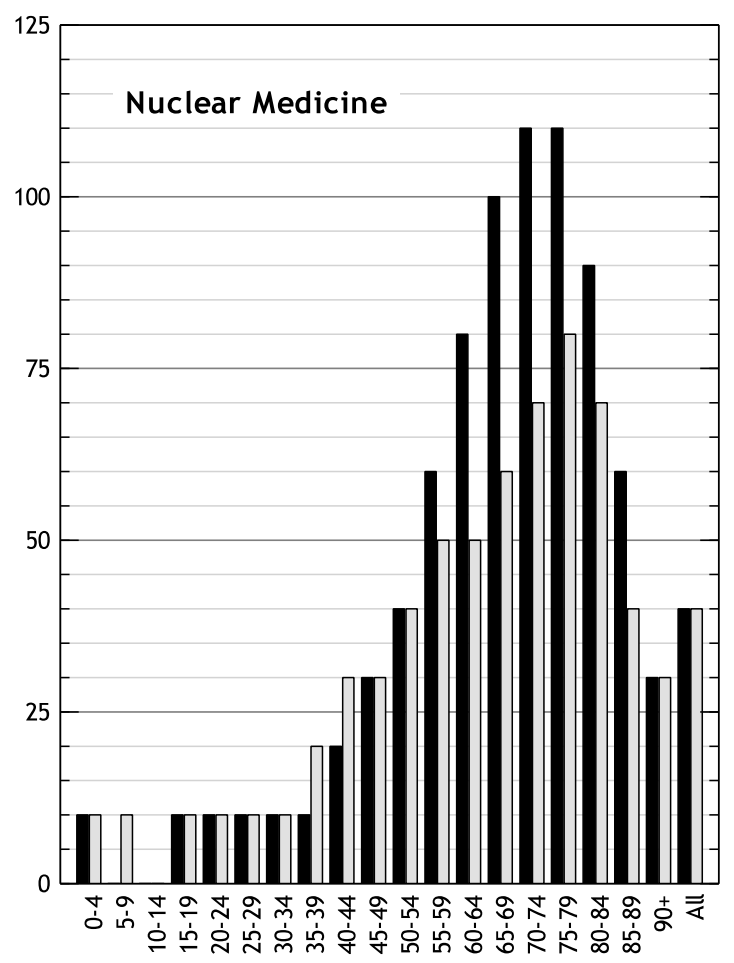

Age (years)

Fig. 4. Age and sex distribution of the mean number of radiodiagnosis examinations per 1000 exposed individuals, for various imaging modalities: conventional radiology (top left), dental radiology (top right), computed tomography (bottom left) and nuclear medicine (bottom right).

of examinations with age of the exposed individual. The mean number of examinations for 1000 individuals varies considerably, rising from around 1720 for young children to around 3800 for elders aged 80 years and more. The peak observed in Figure 2 for the generation aged 10-19 is reduced in Figure 3, but is nevertheless visible on the mean number of examinations for children aged 10-14 years. Within the exposed population, the exposure accumulated over the year is very heterogeneous: per individual exposed, the median effective dose is $0.08 \mathrm{mSv}$ whereas the average effective dose is equal to $3.4 \mathrm{mSv}$. Indeed 


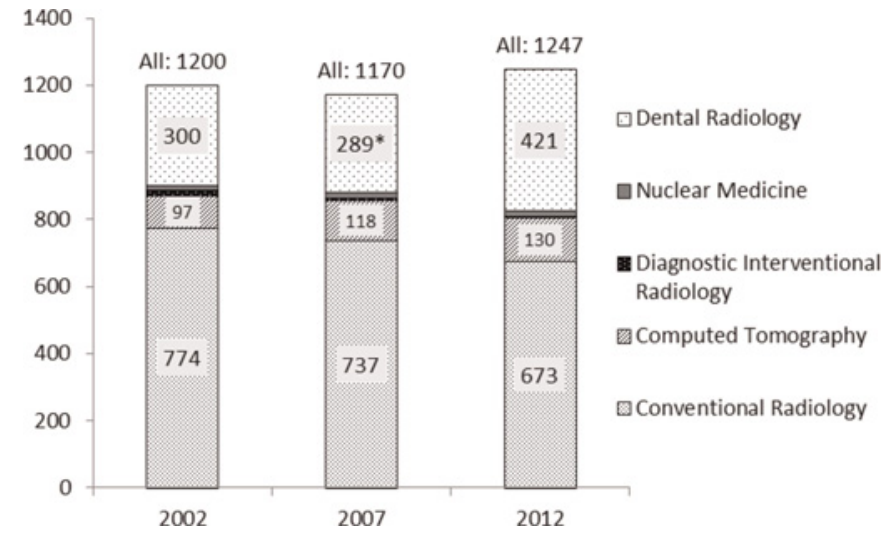

Fig. 5. Evolution of the average number of radiodiagnosis examinations per 1000 inhabitants in France between 2002 and 2012, for the different imaging modalities. *Based on 2002 data, presumably underestimated.

$70 \%$ of exposed individuals received less than $1 \mathrm{mSv}, 18 \%$ received between 1 and $10 \mathrm{mSv}, 11 \%$ received between 10 and $50 \mathrm{mSv}$ and $1 \%$ received more than $50 \mathrm{mSv}$. Similarly, the exposure strongly depends on the age of the individual: below $1 \mathrm{mSv}$ before 20 years, around $2.5 \mathrm{mSv}$ at 45 years and around $7 \mathrm{mSv}$ at 75 years.

The characteristics of exposure vary greatly with age and sex, as illustrated in Figure 4. Exposure of children aged less than 5 years is mainly due to the conventional radiology, with 1600 procedures for 1000 children exposed $(70 \%$ of these procedures concern the thorax and the limbs). During adolescence, conventional radiology and dental radiology make up almost all of the exposure (respectively 1020 and 1220 procedures for 1000 individuals exposed). Girls tend to undergo slightly more dental radiology procedures than boys, who in turn benefit from more conventional radiology examinations than girls.

In the adult population, conventional radiology is more common for women, with an average of $20 \%$ more procedures by exposed individual than men. This difference is due mainly to mammograms, but also to additional limbs examinations. On the contrary, computed tomography and nuclear medicine procedures are much more frequent in men than in women (45\% more CT and 40\% more nuclear medicine examinations in average per exposed individual). These disparities are explained mainly by extra thorax and abdomen-pelvis scanners, as well as cardiac scintigraphies in men after 50 years old.

Figure 5 depicts the evolution of the average number of radiodiagnosis examinations per 1000 inhabitants and per year between 2002 and 2012. All modalities altogether, an increase of almost $4 \%$ is observed over the decade. This is mainly due to an important rise in dental radiology $(40 \%$ over the same period) and to a lesser extent to computed tomography (34\%). Conventional radiology remains the most frequent type of radiodiagnosis examination but nevertheless decreases by $13 \%$. It has to be pointed out that as the EGB database could not be considered as representative for dental radiology procedures before 2012, the number of dental radiology procedures for 2002 was established after a survey conducted by health insurances. The number of dental radiology procedures for 2007 was taken almost equal to 2002, therefore the calculated frequency for dental radiology in 2007 can be considered as strongly under evaluated.

The average individual effective dose has increased by $20 \%$ between 2007 and 2012, from $1.3 \mathrm{mSv}$ to $1.6 \mathrm{mSv}$. This increase - much less important than that of the previous period ( $+57 \%$ between 2002 and 2007) - can be mostly explained by an increase of $10 \%$ in the number of computed tomography examinations per inhabitant between 2007 and 2012; and by a better knowledge of clinical practices and delivered doses, particularly for computed tomography. The 2012 average exposition of the French population related to radiodiagnosis examinations sits in the higher third of the European countries (European Commission, 2015), but remains much lower than Belgium, the EU country where the population is most exposed (2.7 $\mathrm{mSv}$ per year and per inhabitant in 2013).

\section{Conclusion}

Numerous actions have been taken in recent years at the national level to harmonize and optimize the doses delivered to patients during radiodiagnosis examinations, such as the establishment of procedures guides by professionals, their regulatory training to radiation protection of patients as well as the update of diagnostic reference levels. To meet the goal of reduction of the delivered doses, clearly announced by the French ministry of health's Plan Cancer 2014-2019, these efforts must continue. In accordance with the basic principles of the radiation protection of patients, specific interest should be paid to the justification of certain examinations which have particularly increased in numbers, such as dental radiology (even if the actual increase is lower than the one reported here, due to limitations with EGB's representativeness in previous studies). Likewise, the increase in computed tomography examinations is to be analysed in the light of the decrease in conventional radiology procedures and of the expected medical benefits of cross-sectional imaging. The possible substitution of a part of computed tomography examinations by magnetic resonance imaging would contribute significantly to moderate the increase in the exposure of the population at the national level. The recent technical evolutions of CT scanner, such as iterative reconstruction or improved detector efficiency, which came into clinical use mainly after 2012, are also expected to play an important role for dose control. However, more efforts are still needed in the optimization of delivered dose and in the harmonization of practices, whatever the imaging field.

\section{References}

De Roquefeuil L, Studer A, Neumann A, Merlière Y. 2009. Léchantillon généraliste de bénéficiaires: représentativité, portée et limites. Prat. Organ. Soins 40: 213-223.

Etard C, Aubert B. 2012. Enquête nationale en médecine nucléaire : radiopharmaceutiques et activités utilisés en 2007 en secteur public. Med. Nucl. 36: 53-61.

Etard C, Celier D, Roch P, Aubert B. 2012a. National survey of patient doses from whole-body FDG PET-CT examinations in France in 2011. Radiat. Prot. Dosim. 152, 334-338.

Etard C, Sinno-Tellier S, Empereur-Bissonnet P, Aubert B. 2012b. French population exposure to ionizing radiation from diagnostic medical procedures in 2007. Health Phys. 102: 670-679. 
European Commission. 2008. European guidance on estimating population doses from medical X-ray procedures. Radiation Protection $\mathrm{N}^{\circ} 154$.

European Commission. 2015. Medical radiation exposure of the European population. Radiation Protection $\mathrm{N}^{\circ} 180$. DOI:10.2833/ 708119.

EU Council. 1997. Council Directive 97/43/Euratom of 30 June 1997 on health protection of individuals against the dangers of ionizing radiation in relation to medical exposure, and repealing Directive 84/466/Euratom. Off. J. Eur. Union L 180: 22-27.

EU Council. 2013. Council Directive 2013/59/Euratom of 5 December 2013 laying down basic safety standards for protection against the dangers arising from exposure to ionising radiation, and repealing Directives 89/618/Euratom, 90/641/Euratom, 96/29/ Euratom, 97/43/Euratom and 2003/122/Euratom. Off. J. Eur. Union L 13: 1-73.

Georges J-L, et al. 2014. Patient exposure to X-rays during coronary angiography and percutaneous transluminal coronary intervention: results of a Multicenter National Survey. Catheter. Cardio. Inte. 83(5): 729-738.

HAS. 2006. Guide des indications et des procédures des examens radiologiques en odontostomatologie. Recommandations pour les professionnels de santé. Haute Autorité de Santé report. Published online 01.05.2006: http:/www.has-sante.fr/portail/jcms/c_611221/ fr/guide-des-indications-et-procedures-des-examens-radiologi ques-en-odonto-stomatologie.

IRSN. 2006. Exposition médicale de la population française aux rayonnements ionisants. Joint IRSN-INVS report. Published online 18.04.2006: http://www.irsn.fr/FR/expertise/rapports_ex pertise/Documents/radioprotection/IRSN_INVS_2006_Exposi tion_medicale_population_rayonnements_ionisants.pdf.

IRSN. 2010. Exposition de la population française aux rayonnements ionisants liée aux actes de diagnostic médical en 2007. Joint IRSNINVS report. Published online 22.03.2010: http://www.irsn.fr/FR/ expertise/rapports_expertise/Documents/radioprotection/ IRSN_INVS_Rapport_Expri_032010.pdf.

IRSN. 2011. Doses délivrées aux patients en scanographie et en radiologie conventionnelle - Résultats d'une enquête multi- centrique en secteur public. IRSN report DRPH/SER N²010-12. Published online 09.05.2011: http://www.irsn.fr/FR/expertise/ rapports_expertise/Documents/radioprotection/IRSN-Rapportdosimetrie-patient- 2010-12. pdf.

IRSN. 2013. Analyse des données relatives à la mise à jour des niveaux de référence diagnostiques en radiologie et en médecine nucléaire : bilan 2009-2010. IRSN report PRP-HOM N²012-12. Published online 04.04.2013: http://www.irsn.fr/FR/expertise/ rapports expertise/Documents/radioprotection/IRSN_PRPHOM-2012-12 Bilan-NRD- 2009-2010. pdf.

IRSN. 2014a. Exposition de la population française aux rayonnements ionisants liée aux actes de diagnostic médical en 2012. IRSN report PRP-HOM N²014-6. Published online 13.10.2014: http://www.irsn.fr/FR/expertise/rapports_expertise/Documents/ra dioprotection/IRSN-PRP-HOM-2014-6_Exposition-Francerayonnements-diagnostic-medical-2012.pdf.

IRSN. 2014b. Doses délivrés aux patients en scanographie - Analyse des recueils de doses de 9 services de radiologie en France en 2012. IRSN report PRP-HOM N ${ }^{\circ} 2013-12$. Published online 03.01.2014: http://www.irsn.fr/FR/expertise/rapports_expertise/ Documents/radioprotection/IRSN_PRP-HOM-2013-12_Dosespatients-scanographie-2012.pdf.

SFMN. 2012. Guide des procédures - examens diagnostiques. Société Française de Médecine Nucléaire. Published online: http:// www.sfmn.org/index.php/la-societe/guides-des-procedures-exam ens-diagnostiques.

SFR. 2004. Les procédures radiologiques : réalisation, critères de qualité et optimisation. Société Française de Radiologie, Office de Protection contre les Rayonnements Ionisants et Institut de Radioprotection et de Sûreté Nucléaire. Published online: http:// www.sfrnet.org/sfr/professionnels/5-referentiels-bonnes-pra tiques/guides/guide-procedures-radiologiques/index.phtml.

SFR. 2013. Guide pratique d'imagerie diagnostique à l'usage des médecins radiologues. Société Française de Radiologie. Published online 07.03.2013: http://www.sfrnet.org/sfr/profession nels/5-referentiels-bonnes-pratiques/guides/guide-pratique-dimagerie-diagnostique-a-lusage-des-medecins-radiologues/arti cle.phtml?id=rc/org/sfrnet/htm/Article/2013/20130222- 140219-813.

Cite this article as: Dreuil S, Etard C. 2017. Exposure of the French population to ionizing radiations from medical diagnostic procedures in 2012. Radioprotection 52(1): 45-49. 